\title{
AN UNUSUAL CASE
}

\section{OP \\ WARTY GROWTHS ON THE FACE.}

BY

GEORGE THIN, M.D.

(Received March 8th-Read April 26th, 1881.)

I SHOWED at a recent meeting of the Society the subject of a skin disease, which although perhaps frequently met with in its common varieties is, I imagine, very rarely developed in the manner and to the degree exemplified in this patient.

I believe the case worthy of being described to the Society because I am not aware that there is a portrait which shows similar appearances in any of the Skin Atlases. Amongst the several physicians and sargeons of much experience in diseases of the skin, to whom I showed the patient privately, there was no unanimity of opinion regarding its nature, and none of them could recall ever having seen a similar case.

I am further encouraged to bring it before the Society by the fact that its nature has been established by microscopical examination, and should a similar case come again under observation the diagnosis would not be so open to doubt as it was in this instance. 
The patient, a healthy, young, unmarried woman, æt. 21, was introduced to me by her medical attendant, Dr. William Stewart, under whose care she still remains.

Any one looking suddenly at this person's face for the first time might get the impression that she was suffering from confluent smallpox. A closer examination shows that the whole face is covered with an eruption of small flat papules, slightly raised above the level of the skin and very thickly set everywhere, but more especially on the chin and lower parts of the cheeks. At some parts, near the mouth and on the chin, the papules have coalesced into small patches, but even in these the outlines of the original papules can be made out (see Plate V).

The term papule is used without prejudice. To be more minute, the papules consist of small rounded elevations, which feel hard to the touch and are of a brownish colour. They do not scale, are dry, many (but not all of them) depressed in the centre, produce no symptoms, and have no surrounding reactionary zone. The smallest are quite round, the largest ones more or less angular. When looked at through a magnifying glass some of them show minute red points. The very small ones are under the sixteenth of an inch in diameter, small ones about the twelfth of an inch, but the majority about the tenth of an inch. Having attained the latter size they did not grow larger, and they all remained only slightly elevated above the level of the skin. The face became covered by the continual growth of new ones until it attained its present appearance. The combined area of the growths now much surpasses the combined area of the unaffected skin. None of them have disappeared.

The distribution is peculiar. Until quite recently they were entirely limited to the face proper. The affected area was bounded by the hair of the scalp, the angles of the lower jaw, and the border of the jaw towards the chin. This was the case when I first saw her in the summer of 1880. About Christmas of the same year I found several on the skin of the neck beneath the chin, but the scalp 
and other parts of the neck remained free. The lower eyelids and a small tract of skin below and external to them are free.

As regards the papules themselves, the most marked features are the colour, the elevation, size, shape, and great number.

They began to appear on the chin in 1877; after some time- they went up the sides of the face, gradually encroached on the nose, then appeared on the forehead, and finally, on the upper part of the cheeks.

In 1879 they began to appear on the back of the right hand, where, on the 5th November, 1880, I counted thirtynine. About the beginning of 1880 they were first noticed on the back of the left hand, where, on the date referred to, they were fewer in number than on the right.

Those on the hands were similar in size and general appearance to those on the face.

The rest of the body was entirely free from them, with the solitary exception of one that appeared on the bend of the right elbow in October, 1880.

My first impression of the case was that the disease was an epidermic growth-a kind of wart-and I attempted to scrape some of them off on the first occasion on which I saw the patient. The treatment was not tolerated, and new growths subsequently replaced those which had been removed. Their great number, their comparatively smooth or cup-shaped surface, and uniformity as to size were all characters which distinguished them from common warts, an opinion in which further I could obtain support from very few of my colleagues to whom I showed the patient. Microscopical examination of one of the small growths showed, however, that this opinion was correct, and that the papules were really small epidermic tumours, characterised by long narrow papillm and deep broad interpapillary projections. On the surface of these projections the horny epidermis was thicker and less homogeneous than in normal skin.

The connective tissue immediately beneath the growth was unchanged. 
There was very slight cell exudation in the papillary layer immediately under the epidermis and a considerable amount in the elongated papillæ.

The changes in the epidermis being much in excess of those found in the connective tissue, I am disposed to look on the latter as being secondary to the former. The microscopical examination threw no light on the canse of the epidermic growth.

The distribution of these tumours on the face and on the backs of the hands has no relation to any distribution of nerves or blood-vessels, but their appearance first on the face, and then on the hands, does suggest a possibility of auto-inoculation.

Hebra, in his work on 'Skin Diseases' ('Hautkrankheiten,' Erster Band, Zweite Lieferung, second edition, p. 31), remarks that he has seen cases in which a large number of warts developed simultaneously on different parts of the body, mostly on the face, to such an extent that they might have been mistaken for the eruption of some other skin disease. They remain for several months and then disappear.

In the case which I have described their appearance was slow, gradual, but continued, and up to the present time (a period of three years' duration) not one has disappeared. A variety of local applications and a long course of arsenic have been tried without effect. 


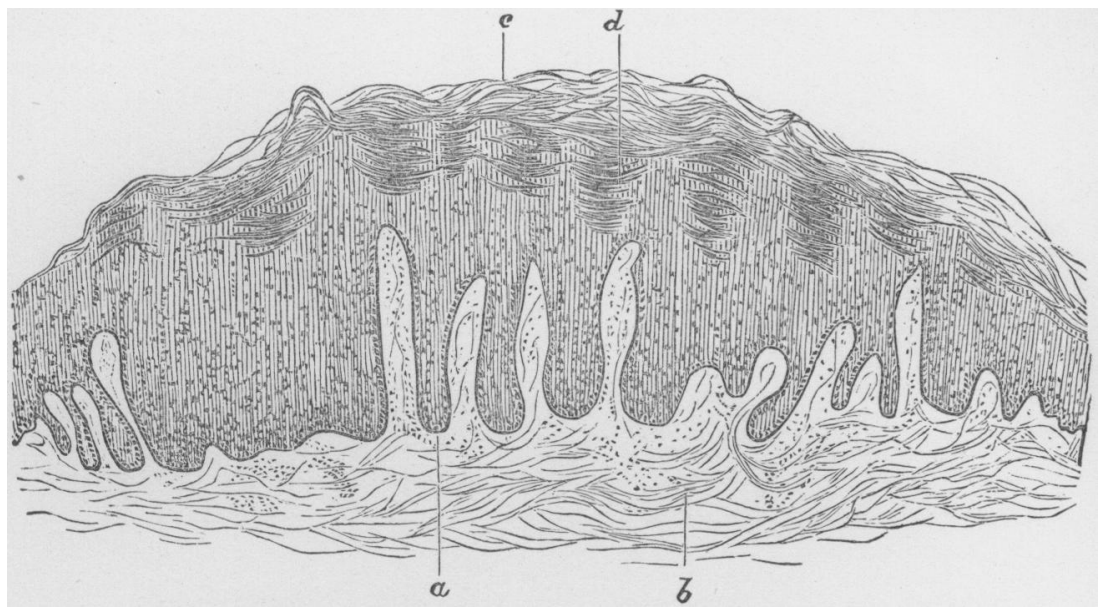

FIG. 1.-Microscopical appearance : vertical section through the whole of a growth which was excised from the back of the hand. $\times 45$.

$a$, lower border of rete; $b$, connective tissue ; $c$, horny layer of epidermis ; $d$, horny layer penetrating downwards to an unusual depth.

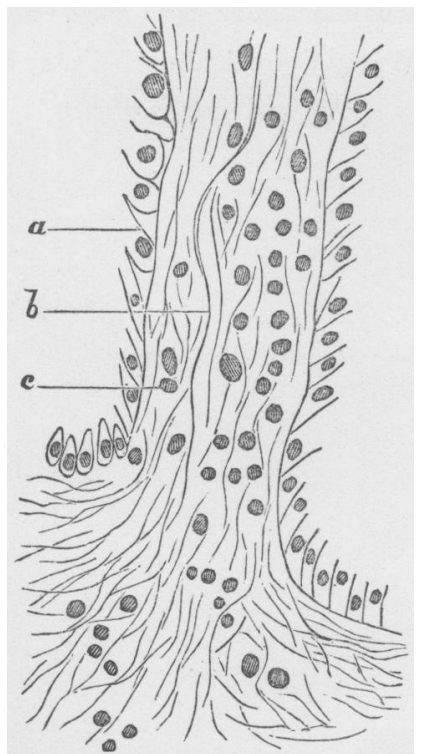

F1G. 2.-Microscopical appearance : lower part of a papilla, illustrating the cell-exudation present. $\times 260$.

$a$, deep columnar cells of rete; $b$, capillary blood-vessel in papilla ; $c$, exudation cells. 


\section{DESCRIPTION OF PLATE V.}

Case of Warty Growths in the Face; natural size.

(George Thin, M.D.) 


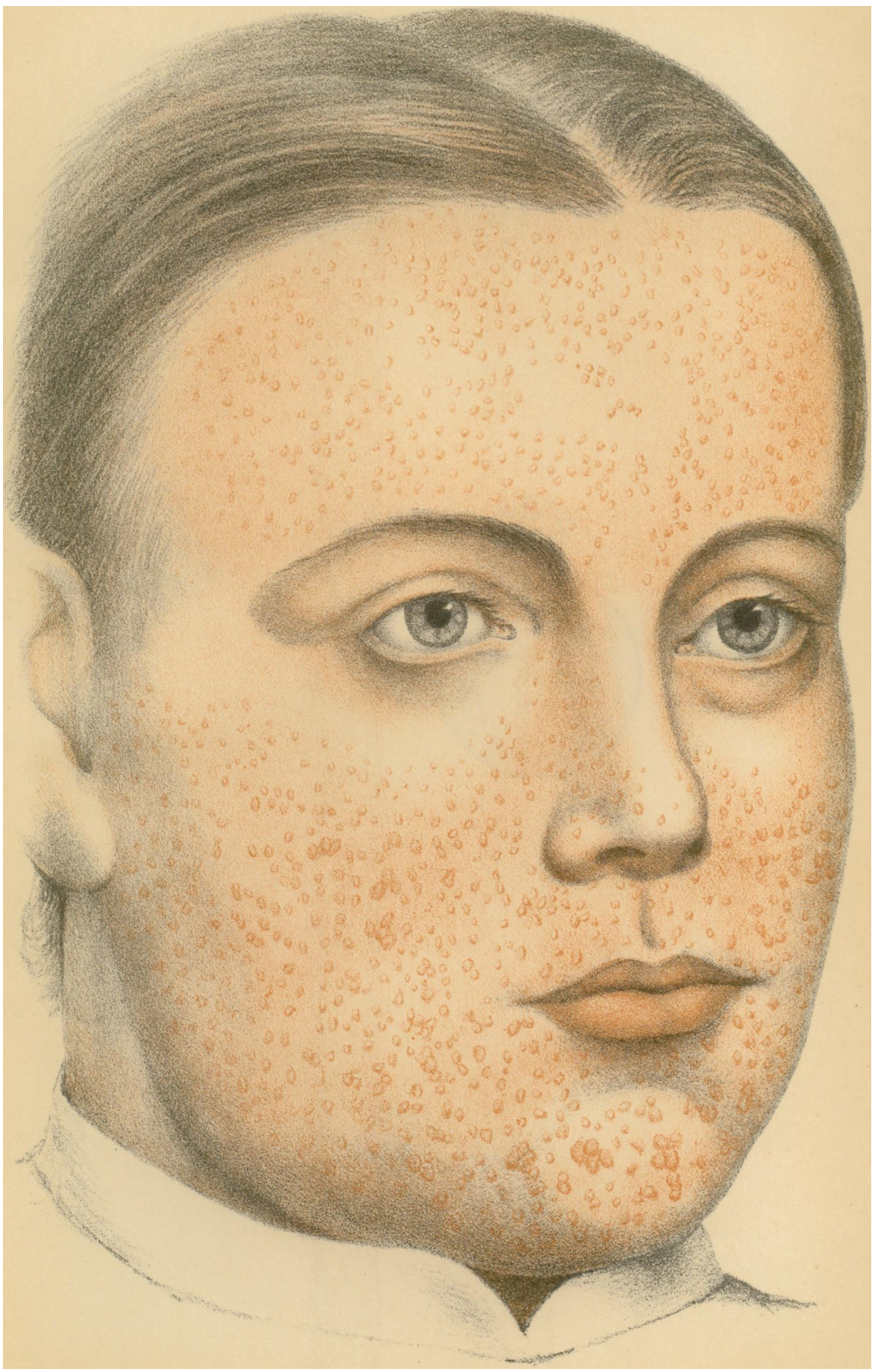

it. arr taros thrumo ath. 